\title{
Oxalate loading test: a screening test for steatorrhoea
}

\author{
D. S. RAMPTON ${ }^{1}$, G. P. KASIDAS, G. ALAN ROSE, AND MARTIN SARNER ${ }^{2}$ \\ From University College Hospital, London, St. Peter's Hospitals and Institute of Urology, London
}

SUMMARY To investigate the possibility of measuring urinary oxalate output instead of faecal fat excretion as an outpatient screening test for steatorrhoea, we determined 24 hour urinary oxalate and five day faecal fat excretion before and during an oral load of sodium oxalate $600 \mathrm{mg}$ daily (oxalate $4.44 \mathrm{mmol}$ ), in 32 patients with suspected malabsorption on a diet containing oxalate $30 \mathrm{mg}$ $(0.33 \mathrm{mmol})$, fat $50 \mathrm{~g}(180 \mathrm{mmol})$, and calcium $1 \mathrm{~g}(25 \mathrm{mmol})$. Nineteen patients proved to have steatorrhoea (mean faecal fat $62 \mathrm{mmol} / 24 \mathrm{~h}$, range 19-186 mmol) of varying aetiologies. On the diet alone, urinary oxalate was raised in only nine of these patients (mean $0.25 \mathrm{mmol} / 24 \mathrm{~h}$, range $0.08-0.59 \mathrm{mmol}$ ) (normal $<0.20$ ). By contrast, when the diet was supplemented with oral sodium oxalate, all 19 patients with steatorrhoea had hyperoxaluria (mean $0.91 \mathrm{mmol} / 24 \mathrm{~h}$, range 0.46 $1.44 \mathrm{mmol}$ ) (normal $<0.44$ ). There was a significant positive linear relationship between urinary oxalate and faecal fat when the 32 patients were on the high oxalate intake $(r=0.73, \mathrm{P}<0.001)$, but not when they were on the low oxalate intake. Mean percentage absorption of orally administered oxalate was $5.8 \pm 0.9 \%( \pm 1 \mathrm{SD})$ in normal subjects and $14.7 \pm 6.0 \%(\mathrm{P}<0.002)$ in patients with steatorrhoea. Measurement of urinary oxalate output during oral sodium oxalate loading appears to be a reliable and convenient screening test for steatorrhoea.

As a screening test for malabsorption, estimation of faecal fat excretion is inconvenient, tedious, and aesthetically unpleasant, both for the patient and the clinical laboratory. Although the need for prolonged collection periods may be reduced by the use of inert markers (Simpson et al., 1978), patient compliance in the ingestion of these, in the consumption of a diet of fixed fat content, and in the faecal collection itself, may be hard to obtain. Because of these limitations, doctors may be reluctant to request faecal fat estimations, particularly for excluding malabsorption. Several alternative screening procedures have therefore been proposed (Losowsky et al., 1974), but so far none has proved sufficiently simple or reliable to receive widespread acceptance for routine clinical use.

Enteric hyperoxaluria was first reported in patients with ileal disease or resection (Dowling $e t$ al., 1971; Admirand et al., 1971; Smith et al., 1972) but has since been described in a wide variety of other digestive and absorptive disorders characterised by malabsorption of fat, bile acids, or both.

'Present address: Gastroenterology Unit, Guy's Hospital Medical School, London SE1.

'Address for reprint requests: Dr Martin Sarner, Gastroenterology Unit, University College Hospital, London WC1. Received for publication 27 June 1979
Although it appears to be a consequence of excessive absorption of dietary oxalate (Chadwick et al., 1973; Stauffer et al., 1973; Earnest et al., 1974), the precise mechanism of enteric hyperoxaluria is uncertain.

The colon is probably the site of the hyperabsorption, and it has been suggested that its permeability to oxalate is increased by malabsorbed bile acids and fatty acids (Saunders et al., 1975; Dobbins and Binder, 1976, 1977; Fairclough et al., 1977). A positive linear relationship exists between urinary oxalate output and the degree of steatorrhoea in patients with ileopathy (Andersson and Jagenburg, 1974; Earnest et al., 1974; Hylander et al., 1978), coeliac disease (McDonald et al., 1977), and other causes of fat malabsorption (Ruge et al., 1976; Andersson and Gillberg, 1977; Stauffer, 1977). This correlation accords with the solubility theory, which holds that malabsorbed fatty acids form soaps with intraluminal calcium, thereby increasing the amount of soluble oxalate available for absorption (Andersson and Jagenburg, 1974; Earnest et al., 1974; McDonald et al., 1977).

Because of the correlation between urinary oxalate output and faecal fat excretion, we have assessed the value of estimating urinary oxalate during a standardised oxalate load as a screening test for 
steatorrhoea (Andersson and Gillberg, 1977). In 32 patients with suspected malabsorption we measured 24 hour urinary oxalate outputs, using a specific enzymatic method, before and during an oral load of sodium oxalate; a simultaneous five day faecal collection was made for fat analysis. the Ethical Committee at University College Hospital.

DIET

Throughout the study, each subject took a diet containing oxalate $30 \mathrm{mg}$ (range $26-44 \mathrm{mg})(0.33$

Table Faecal fat, urinary oxalate, percentage oxalate absorption and urinary glycollate in normal subjects and in patients with and without steatorrhoea on low oxalate intake $(A)(0.33 \mathrm{mmol})$ and high oxalate intake $(B)(4 \cdot 77 \mathrm{mmo} \mathrm{l})$

\begin{tabular}{|c|c|c|c|c|c|c|c|}
\hline & $N$ & $\begin{array}{l}\text { Faecal fat } \\
(\mathrm{mmol} / 24 \mathrm{~h})\end{array}$ & $\begin{array}{l}24 \text { h urine } \\
\text { oxalate }(A) \\
(\text { mmol } \mid 24 h)\end{array}$ & $\begin{array}{l}24 \text { h urine } \\
\text { oxalate }(B) \\
(\text { mmol } / 24 h)\end{array}$ & $\begin{array}{l}\text { Percentage } \\
\text { oxalate } \\
\text { absorption }\end{array}$ & $\begin{array}{l}24 \text { h urine } \\
\text { glycollate }(A) \\
(\mathrm{mmol} / 24 \mathrm{~h})\end{array}$ & $\begin{array}{l}24 \text { h urine } \\
\text { glycollate }(B) \\
(\mathrm{mmol} / 24 \mathrm{~h})\end{array}$ \\
\hline Normal subjects & 10 & - & $0.14 \pm 0.03$ & $0.40 \pm 0.02 \dagger \ddagger$ & $5 \cdot 8 \pm 0 \cdot 9$ & $0.25 \pm 0.08$ & $0.24 \pm 0.08$ \\
\hline \multicolumn{8}{|l|}{ Patients with steatorrhoea } \\
\hline Pancreatic insufficiency & 5 & $66 \cdot 0 \pm 46 \cdot 1$ & $\begin{array}{l}0.24 \pm 0.11^{*} \\
0.28 \pm 0.19\end{array}$ & $\begin{array}{l}0.69 \pm 0.23+\mp \\
0.95 \pm 0.22 \dagger \ddagger\end{array}$ & $\begin{array}{l}10 \cdot 1 \pm 5 \cdot 1 \\
15 \cdot 1 \pm 6 \cdot 0 \dagger\end{array}$ & $\begin{array}{l}0.21 \pm 0.06 \\
0.26 \pm 0.06\end{array}$ & $\begin{array}{l}0.20 \pm 0.05 \\
0.27 \pm 0.05\end{array}$ \\
\hline Coeliac disease & 5 & $52 \cdot 4 \pm 27 \cdot 0$ & $0 \cdot 18 \pm 0.06$ & $0.84 \pm 0.30 † \ddagger$ & $14 \cdot 7 \pm 6 \cdot 8 \dagger$ & $0 \cdot 18 \pm 0.07$ & $0.19 \pm 0.07$ \\
\hline Miscellaneous & 4 & $84 \cdot 4 \pm 69 \cdot 3$ & $0.33 \pm 0.16$ & $1 \cdot 21 \pm 0.17 \dagger$ & $19 \cdot 8 \pm 1 \cdot 3 \dagger$ & $0 \cdot 19 \pm 0.09$ & $0.18 \pm 0.06$ \\
\hline All & 19 & $62 \cdot 0 \pm 44 \cdot 6$ & $0.25 \pm 0.14 \dagger$ & $0.91 \pm 0.29+\delta$ & $14 \cdot 7 \pm 6 \cdot 0 \dagger$ & $0.21 \pm 0.07$ & $0.21 \pm 0.06$ \\
\hline \multicolumn{8}{|c|}{ Patients with normal faecal fat } \\
\hline Crohn's disease & 5 & $9.9 \pm 3.9$ & $0.27 \pm 0.09 \dagger$ & $0.53 \pm 0.18 \ddagger$ & $5 \cdot 9 \pm 3 \cdot 0$ & $0.21 \pm 0.07$ & $0.21 \pm 0.07$ \\
\hline Miscellaneous & 8 & $8 \cdot 5 \pm 4 \cdot 5$ & $0.16 \pm 0.06$ & $0 \cdot 40 \pm 0 \cdot 16 \$$ & $5 \cdot 5 \pm 2 \cdot 5$ & $0.21 \pm 0.09$ & $0 \cdot 19 \pm 0 \cdot 10$ \\
\hline All & 13 & $9 \cdot 1 \pm 4 \cdot 1$ & $0.20 \pm 0.09$ & $0.45 \pm 0.17 \|$ & $5 \cdot 7 \pm 2 \cdot 5$ & $0.21 \pm 0.08$ & $0.20 \pm 0.09$ \\
\hline
\end{tabular}

$\mathrm{N}$ : number of subjects. All values expressed as mean \pm SD. Significant difference from normal subjects: ${ }^{*} \mathrm{P}<0.05, \dagger \mathrm{P}<0.01$. Significant

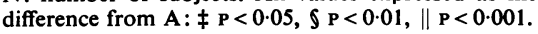

\section{Methods}

SUBJECTS

Thirty-two patients (aged 21-73 years) with suspected malabsorption were studied (Table). Of the 19 who proved to have steatorrhoea, five patients had Crohn's disease without radiological evidence of colonic involvement (three had had resection of the terminal ileum and part of the ascending colon), five patients had coeliac disease, and five had pancreatic exocrine insufficiency; the remaining four patients had jejunal diverticulosis, a partial gastrectomy, a jejunoileal bypass for obesity, and extensive small bowel resection after trauma. Of the 13 patients without steatorrhoea, five had Crohn's disease without evidence of colonic disease (two had had terminal ileal resection and right hemicolectomy), three had irritable bowel syndrome, and the remaining five patients had coeliac disease, recurrent acute pancreatitis, giardiasis, lactose intolerance, and a steroid-responsive diarrhoea 10 years after removal of a chromophobe adenoma.

Ten normal volunteers (aged 19-62 years) served as controls for urinary oxalate and glycollate excretion.

Twenty of the patients were investigated in hospital; the remaining 12 patients and all the normal subjects were studied as outpatients. All subjects had normal renal function and none showed clinical evidence of pyridoxine deficiency (Admirand et al., 1971). Each subject gave informed consent to the study, approval for which was obtained from $\mathrm{mmol})$, fat $50 \mathrm{~g}(48-56 \mathrm{~g})(180 \mathrm{mmol})$, and calcium $1000 \mathrm{mg}(990-1130 \mathrm{mg})(25 \mathrm{mmol})$. Each subject was issued with detailed diet sheets and was specifically advised to avoid ascorbic acid intake in excess of that taken in the diet. Before the beginning of the study period, outpatient and normal volunteers were individually instructed in the use of the diet sheets; a dietician prepared and supervised the consumption of the inpatients' diet.

\section{OXALATE LOAD}

Sodium oxalate was supplied in gelatin capsules, each containing $300 \mathrm{mg}$ (oxalate $2 \cdot 22 \mathrm{mmol}$ ). One capsule was taken during lunch and a second during supper on each of days five, six, and seven of the study. The contents of each capsule were dissolved in $200 \mathrm{ml}$ of water and taken with the food. This gave a daily supplement to dietary oxalate intake of $4.44 \mathrm{mmol}$ of oxalate.

All treatments were kept unchanged during the study period, and no subjects were on therapy known to affect urinary oxalate output other than by reducing faecal fat excretion.

\section{PROTOCOL}

Each study lasted seven days, throughout which time the subjects were on the diet. On days 3-7 inclusive, a five day faecal fat collection was made. On day 4, a 24 hour urine collection (A) was made for estimation of urinary oxalate on the low oxalate intake. On days 5-7 inclusive, the loading test was 
carried out, the subjects taking sodium oxalate $300 \mathrm{mg}$ twice daily with their meals, and on day 7 collecting a second 24 hour urine specimen (B), while still taking the oxalate load.

\section{ANALYTICAL METHODS}

Urinary oxalate

Urine was collected into $10 \mathrm{ml} 6 \mathrm{~N}$ hydrochloric acid; on completion of the collection, aliquots, to which thymol was added, were frozen until analysis. Oxalate was determined in duplicate using the specific oxalate decarboxylase method of Hallson and Rose (1974). Recovery of oxalate added to normal urine was $98 \pm 5 \cdot 1 \%(n=12)($ mean \pm 1 SD) and the coefficient of variation of repeated estimations of the same sample was $3.4 \%(n=12)$. Recovery experiments on samples obtained from those patients on drug therapy showed that their medication did not stimulate or inhibit oxalate decarboxylase activity.

\section{Urinary glycollate}

The same urine samples were analysed for glycollate using a glycollate oxidase method (Kasidas and Rose, 1979). Recovery of glycollate added to normal urine was $96 \pm 3.9 \%(n=12)($ mean \pm 1 SD), and the coefficient of variation of repeated estimations was $5 \cdot 8 \%(n=12)$.

\section{Urinary creatinine}

This was measured by the Jaffé reaction (Varley, 1967) in order to assess completeness of urine collections. Twenty-four hour urine creatinine content showed a within patient coefficient of variation between collections $A$ and $B$ of $7 \cdot 2 \%$.

\section{Faecal fat}

Faecal fat was measured by the method of Van de Kamer et al. (1949), as modified by Varley (1967). The coefficients of variation of duplicate estimations of normal (range 2-18 mmol/24 h) and steatorrhoeic (range 20-194 mmol/24 h) stool samples were $7 \cdot 3 \%$ $(n=12)$ and $4.7 \%(n=18)$, respectively. Steatorrhoea was defined as a faecal fat output in excess of $18 \mathrm{mmol} / 24 \mathrm{~h}$.

\section{CALCULATIONS}

Percentage absorption, within 24 hours, of orally ingested sodium oxalate (oxalate $4.44 \mathrm{mmol}$ ) was calculated as below:

$$
\frac{\text { urine oxalate B-urine oxalate A }}{4.44} \times 100 \%
$$

The predictive value of a raised urinary oxalate was calculated, as a percentage, from the number of patients who had steatorrhoea and hyperoxaluria divided by the total number of patients with hyperoxaluria. The predictive value of a normal urinary oxalate, similarly, was given by the number of patients with a normal faecal fat and normal urinary oxalate, divided by the total number of those with a normal urinary oxalate.

\section{STASTICAL METHODS}

Results are expressed as means \pm 1 SD. Urinary oxalate output and faecal fat excretion were initially correlated by the method of least squares, but, because residual analysis showed a non-normal distribution of urinary oxalate, Spearman's rank correlation test was used to test the statistical significance of the correlation. Paired and unpaired data were compared by Wilcoxon's signed ranks test (one-tailed), and sum of ranks test (two-tailed), respectively. Urinary creatinine and faecal fat reproducibility was calculated by analysis of variance.

\section{Results}

URINARY OXALATE IN NORMAL SUBJECTS

On a daily intake of $0.33 \mathrm{mmol}$ oxalate, normal

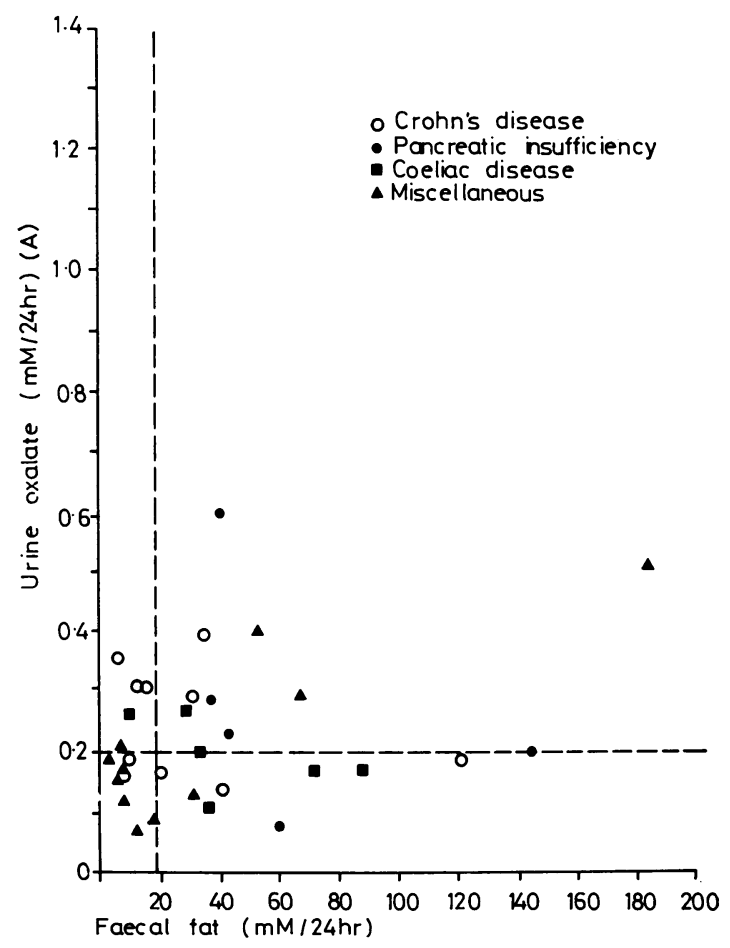

Fig. 1 Relationship between 24 hour urinary oxalate $(A)$ and faecal fat output in patients on a low oxalate intake $(0.33 \mathrm{mmol})$. The dotted lines indicate the upper limit of oxalate excretion (horizontal) and of faecal fat output (vertical) in normal subjects. 
volunteers had a urinary oxalate output (A) of $0.14 \pm 0.03 \mathrm{mmol} / 24 \mathrm{~h}$ (Table). The upper limit of normal was taken as $0.20 \mathrm{mmol} / 24 \mathrm{~h}$ (mean $+2 \mathrm{SD})$. On a high oxalate intake $(4.77 \mathrm{mmol})$, urinary oxalate (B) was $0.40 \pm 0.02 \mathrm{mmol} / 24 \mathrm{~h}$, upper limit 0.44 $\mathrm{mmol} / 24 \mathrm{~h}$.

PATIENTS ON LOW OXALATE INTAKE (A) When on a low oxalate $(0.33 \mathrm{mmol})$ intake, 10 of the 19 patients with steatorrhoea had normal urinary oxalate excretion (Fig. 1). The predictive values of normal and raised oxalates (A) were $44 \%$ and $64 \%$ respectively. There was no significant correlation between urinary oxalate (A) and faecal fat excretion (Spearman's rank correlation coefficient, $r=0 \cdot 20$ ). Five patients, of whom four had steatorrhoea, had urinary oxalates in excess of intake (Fig. 1); two of these had Crohn's disease with a right hemicolectomy, and the three others had pancreatic insufficiency, jejunoileal bypass, and a partial gastrectomy. Although there was a significant difference in urinary oxalate (A) between patients with steatorrhoea and normal volunteers $(P<0.01)$ (Table), individual results in the two groups showed considerable overlap.

PATIENTS ON High OXALATE INTAKE (B)

All patients with steatorrhoea (faecal fat $>18$ $\mathrm{mmol} / 24 \mathrm{~h}$ ) had hyperoxaluria $(>0.44 \mathrm{mmol} / 24 \mathrm{~h})$ when taking $4 \cdot 77 \mathrm{mmol}$ oxalate daily (Fig. 2). Four patients without steatorrhoea (three with Crohn's disease and one with coeliac disease) also had hyperoxaluria. On a high oxalate intake, the predictive value of a normal urinary oxalate (B) was thus $100 \%$, and of a raised urinary oxalate (B) $83 \%$. Urinary oxalate in patients on a high oxalate intake showed a significant positive linear relationship with faecal fat excretion $(r=0.73, P<0.001)$. Urinary oxalate (B) was significantly greater in patients with steatorrhoea than in normal subjects $(P<0.002)$ (Table) and also greater than in patients with normal faecal fat excretion $(P<0.002)$.

PERCENTAGE ABSORPTION OF OXALATE

Percentage absorption within 24 hours of oral sodium oxalate was significantly greater in patients with steatorrhoea $(14 \cdot 7 \pm 6.0 \%)$, compared with those without $(P<0.002)$, and with normal subjects $(5.8 \pm 0.9 \%)(P<0.002)$ (Table). Percentage absorption of oxalate in all patients showed a significant positive linear relationship with faecal fat excretion $(r=0.74, P<0.001)$. Two patients with steatorrhoea, both of whom had had a right hemicolectomy for Crohn's disease, had a percentage absorption of oxalate within the normal range $(<7.6 \%)$; one had minimal steatorrhoea $(19 \mathrm{mmol} / 24 \mathrm{~h})$, and the other

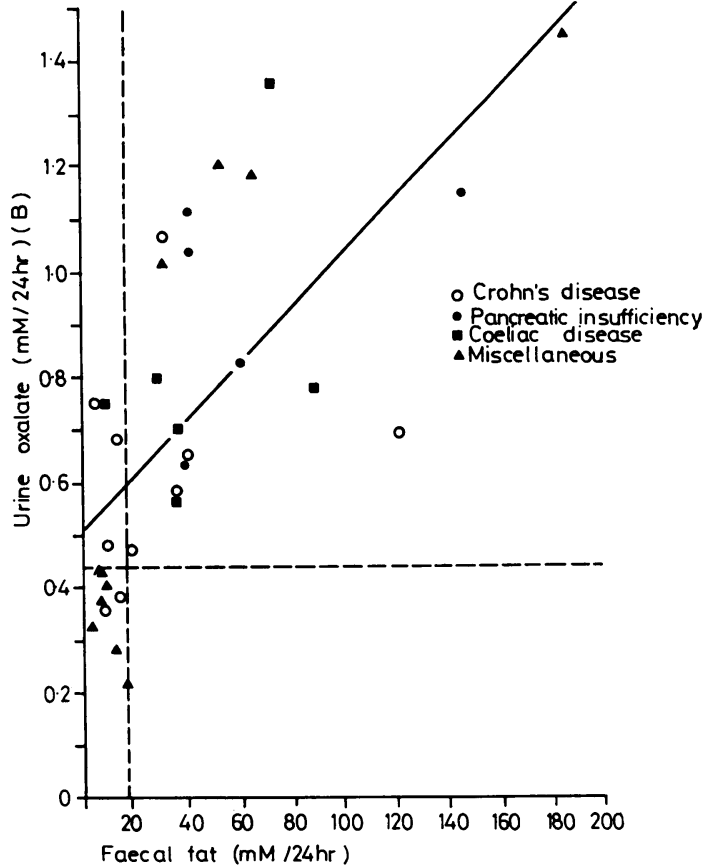

Fig. 2 Relationship between 24-hour urinary oxalate $(B)$ and faecal fat output in patients on a high oxalate intake $(4.77 \mathrm{mmol}),(r=0.73, \mathrm{P}<0.001)$. The dotted lines indicate the upper limit of oxalate excretion (horizontal) and of faecal fat output (vertical) in normal subjects.

had urinary oxalate (A) in excess of his intake $(0.33 \mathrm{mmol})$.

\section{URINARY GLYCOLLATE}

Urinary glycollate was normal in each group studied, whether on high or low oxalate intake (Table). The same finding applied to the five patients in whom urinary oxalate (A) exceeded intake $(0.33 \mathrm{mmol})$ and to the four with hyperoxaluria (B) in the absence of steatorrhoea (urinary glycollates $0 \cdot 18 \pm$ 0.04 and $0.26 \pm 0.11 \mathrm{mmol} / 24 \mathrm{~h}$, respectively).

\section{Discussion}

In this study, all patients with steatorrhoea had hyperoxaluria when given an oral load of sodium oxalate $300 \mathrm{mg}$ twice daily; in contrast, normal urinary oxalate was found in 10 of the steatorrhoeic patients when they were on the low oxalate intake. These results suggest that measurement of urinary oxalate during oral administration of a soluble oxalate load may be a valuable screening test for steatorrhoea.

Shortly after these investigations were started, Andersson and Gillberg (1977) reported similar results using $100 \mathrm{~g}$ spinach as the oxalate load. 
Spinach may not, however, be an ideal source of oxalate. Its content of oxalate, much of which occurs as the insoluble calcium salt, ranges from 4-8.7 $\mathrm{mmol} / 100 \mathrm{~g} \mathrm{(360-780} \mathrm{mg/100} \mathrm{g),} \mathrm{depending} \mathrm{on} \mathrm{the}$ kind and maturity of the sample analysed (Hodgkinson, 1977). Earnest et al. (1975) showed that, in patients with jejunoileal bypass, spinach oxalate may be largely unavailable for absorption; unlike sodium oxalate, spinach failed to produce hyperoxaluria in $30 \%$ of their patients, appearing undigested in the faeces. Finally, in contrast with sodium oxalate, which was well tolerated by our subjects, none of whom noted any side-effects, spinach is unpalatable to some people.

Four of our patients on the high oxalate intake had hyperoxaluria in the absence of steatorrhoea. They were not investigated for bile acid malabsorption, which could theoretically account for the hyperoxaluria of the three patients with Crohn's disease. Other possible explanations for this finding include incompleteness of the faecal collection, consumption of oxalate either unaccompanied by a meal, or in excess of that stipulated, and derivation of an increased proportion of urinary oxalate from other dietary or metabolic precursors. The last two possibilities might also apply to the five patients with urinary oxalates greater than their $0.33 \mathrm{mmol}$ intake, a finding noted by other workers (Chadwick et al., 1973; Stauffer et al., 1973; Andersson and Jagenburg, 1974; Earnest et al., 1974). In each of these patients urinary glycollate was normal (see below).

In support of the solubility theory of the mechanism of enteric hyperoxaluria, we have confirmed the significant linear relationship between faecal fat and urinary oxalate during an oral oxalate load. The absence of such a relationship in patients on a low oxalate intake presumably results from the relatively high contribution to urinary oxalate of non-dietary sources of oxalate in these circumstances. Furthermore, in accordance with earlier workers (Archer et al., 1957; Zarembski and Hodgkinson, 1969; Chadwick et al., 1973; Dobbins and Binder, 1977; Hylander et al., 1978), we have found that, in 24 hours, normal subjects absorb about $6 \%$ of an oral load of soluble oxalate, taken with meals; in patients with fat malabsorption this percentage increases and shows a significant linear correlation with the degree of steatorrhoea. Chadwick et al. (1973) showed that, in normal subjects, percentage excretion in 36 hours of oral ${ }^{14} \mathrm{C}$-oxalate increased from $6.6 \%$ when it was given with food to $28 \%$ when the subject was fasting. We took care to ensure that all our subjects ingested the sodium oxalate with meals.

In all patients studied, urinary excretion of glycollate, measured with an oxidase technique, was within normal limits. This confirms earlier reports (Admirand et al., 1971; Earnest et al., 1974) and provides additional evidence against increased glyoxylate metabolism (Hofmann et al., 1973), type 1 primary hyperoxaluria, and probably also pyridoxine deficiency (Admirand et al., 1971), as causes of hyperoxaluria in these patients.

We conclude that, in patients with most or all of the colon preserved, measurement of the urinary oxalate output, preferably by this specific enzymatic method, during oral administration of sodium oxalate $300 \mathrm{mg}$ twice daily with meals, may be a reliable and convenient screening test for steatorrhoea. The test is equally suitable for both outpatient and inpatient use; further work may demonstrate that strict dietary control is unnecessary and that shorter periods for urine collection and administration of sodium oxalate can be used. The most valuable role of the oxalate loading test may be in the identification, by normal urinary oxalate output, of those patients who do not have steatorrhoea, and in this large group the oxalate loading test may make faecal collection for fat analysis unnecessary.

We thank Ms G. Cave and Ms A. Finch for devising and supervising the diet, Ms C. Chilvers for statistical advice, Ms Margot Fowell for typing the manuscript, Professor F. V. Flynn and Mr K. Piper for their co-operation in the faecal fat estimations, Dr H. A. K. Rowland for referring patients, Mr A. R. Williams and the UCH Pharmacy staff for supplying the sodium oxalate capsules, the nursing staff for their help with inpatients, and finally the patients themselves for participating in the study.

\section{References}

Admirand, W. H., Earnest, D. L., and Williams, H. E. (1971). Hyperoxaluria and bowel disease. Transactions of the Association of American Physicians, 84, 307-312.

Andersson, H., and Gillberg, R. (1977). Urinary oxalate on a high oxalate diet as a clinical test of malabsorption. Lancet, 2, 677-679.

Andersson, H., and Jagenburg, R. (1974). Fat-reduced diet in the treatment of hyperoxaluria in patients with ileopathy. Gut, 15, 360-366.

Archer, H. E., Dormer, A. E., Scowen, E. F., and Watts, R. W. E. (1957). Studies on the urinary excretion of oxalate by normal subjects. Clinical Science, 16, 405-411.

Chadwick, V. S., Modha, K., and Dowling, R. H. (1973). Mechanism of hyperoxaluria in patients with ileal dysfunction. New England Journal of Medicine, 289, 172-176.

Dobbins, J. W., and Binder, H. J. (1976). Effect of bile salts and fatty acids on the colonic absorption of oxalate. Gastroenterology, 70, 1096-1100.

Dobbins, J. W., and Binder, H. J. (1977). Importance of the colon in enteric hyperoxaluria. New England 
Journal of Medicine, 296, 298-301.

Dowling, R. H., Rose, G. A., and Sutor, D. J. (1971). Hyperoxaluria and renal calculi in ileal disease. Lancet, 1, 1103-1106.

Earnest, D. L., Johnson, G., Williams, H. E., and Admirand, W. H. (1974). Hyperoxaluria in patients with ileal resection: an abnormality in dietary oxalate absorption. Gastroenterology, 66, 1114-1122.

Earnest, D. L., Williams, H. E., and Admirand, W. H. (1975). An explanation for the presence or absence of hyperoxaluria in patients with jejuno-ileal bypass (Abstract). Gastroenterology, 68, 1072.

Fairclough, P. D., Feest, T. G., Chadwick, V. S., and Clark, M. L. (1977). Effect of sodium chenodeoxycholate on oxalate absorption from the excluded human colon-a mechanism for 'enteric' hyperoxaluria. Gut, 18, 240-244.

Hallson, P. C., and Rose, G. A. (1974). A simplified and rapid enzymatic method for determination of urinary oxalate. Clinica Chimica Acta, 55, 29-39.

Hodgkinson, A. (1977). Oxalic Acid in Biology and Medicine. Academic Press: London.

Hofmann, A. F., Tacker, M. M., Fromm, H., Thomas, P. J., and Smith, L. H. (1973). Acquired hyperoxaluria and intestinal disease. Evidence that bile acid glycine is not a precursor of oxalate. Mayo Clinic Proceedings, 48, 35-42.

Hylander, E., Jarnum, S., Juel Jensen, H., and Thale, M. (1978). Enteric hyperoxaluria: dependence on small intestinal resection, colectomy and steatorrhoea in chronic inflammatory bowel disease. Scandinavian Journal of Gastroenterology, 13, 577-588.

Kasidas, G. P., and Rose, G. A. (1979). A new enzymatic method for the determination of glycollate in urine and plasma. Clinica Chimica Acta, 96, 25-36.
Losowsky, M. S., Walker, B. E., and Kelleher, J. (1974). Malabsorption in Clinical Practice. Churchill Livingstone: Edinburgh.

McDonald, G. B., Earnest, D. L., and Admirand, W. H. (1977). Hyperoxaluria correlates with fat malabsorption in patients with sprue. Gut, 18, 561-566.

Ruge, W., Köhler, J., and Fromm, H. (1976). Hyperoxalurie als Komplikation bei Darmerkrankungen. Medizinische Klinik, 71, 2028-2032.

Saunders, D. R., Sillery, J., and McDonald, G. B. (1975). Regional differences in oxalate absorption by rat intestine: evidence for excessive absorption by the colon in steatorrhoea. Gut, 16, 543-548.

Simpson, F. G., Hall, G. P., Kelleher, J., and Losowsky, M. S. (1978). Radio-opaque markers for faecal fat (Abstract). Gut, 19, A966.

Smith, L. H., Fromm, H., and Hofmann, A. F. (1972). Acquired hyperoxaluria, nephrolithiasis, and intestinal disease. New England Journal of Medicine, 286, 1371-1375.

Stauffer, J. Q. (1977). Hyperoxaluria and intestinal disease. The role of steatorrhoea and dietary calcium in regulating intestinal oxalate absorption. American Journal of Digestive Diseases, 22, 921-928.

Stauffer, J. Q., Humphreys, M. H., and Weir, G. J. (1973). Acquired hyperoxaluria with regional enteritis after ileal resection. Role of dietary oxalate. Annals of Internal Medicine, 79, 383-391.

Van de Kamer, J. H., Huinink, H., and Weyers, H. A. (1949). Rapid method for the determination of fat in feces. Journal of Biological Chemistry, 177, 347-355.

Varley, H. (1967). Practical Clinical Biochemistry. Heinemann: London.

Zarembski, P. M., and Hodgkinson, A. (1969). Some factors influencing the urinary excretion of oxalic acid in man. Clinica Chimica Acta, 25, 1-10. 